\title{
Letter
}

\section{Open Access Webinars Bring 3R Experts to Your Web Browser: The Berlin Experience}

\author{
Katharina Hohlbaum', Vivian Kral², Christian Zoschke², Bernhard Hiebl³, Monika Schäfer-Korting² \\ and Christa Thöne-Reinekel \\ ${ }^{1}$ Institute of Animal Welfare, Animal Behavior and Laboratory Animal Science, Department of Veterinary Medicine, Freie Universität Berlin, \\ Berlin, Germany; ${ }^{2}$ Institute of Pharmacy (Pharmacology \& Toxicology), Department of Biology, Chemistry, and Pharmacy, Freie Universität Berlin, Berlin, \\ Germany; ${ }^{3}$ Institute for Animal Hygiene, Animal Welfare and Farm Animal Behaviour, University of Veterinary Medicine Hannover Foundation, \\ Hannover, Germany
}

To successfully implement the $3 \mathrm{R}$ (replace, reduce, refine) principle of Russel and Burch (1959) in research, education and training, 3R-relevant knowledge must be improved and multiplied as reported by the Joint Research Center (Holley et al., 2016). Moreover, articles 23 and 24 of Directive 2010/63/EU on the protection of animals used for scientific purposes stipulate that the competence of the personnel involved in the use and care of laboratory animals must be maintained by continuous education (EU, 2010; ${ }^{1}$ ). We need a wide range of education and training opportunities that are freely available in order to meet these requirements and to enable all interested parties to receive sufficient training. Providing open online educational resources in this field is an excellent opportunity to achieve these goals.

We developed a webinar series on $3 \mathrm{R}$ strategies in research and education within the Berlin-Brandenburg research platform $\mathrm{BB} 3 \mathrm{R}^{2}$. The webinar consists of 30 -min lectures followed by a discussion between the expert and the auditorium as well as the online participants at the same time. Attendance is free of charge and participants can choose to join the webinar in the lecture hall or online. Speakers have the opportunity to give their talks in the lecture hall or as a broadcast, which allows inviting expert international speakers.

The first webinars were carried out between 2016 and 2018 at the Freie Universität Berlin (Germany) ${ }^{3}$. Table 1 gives an overview of $3 \mathrm{R}$ topics that were covered so far. The original concept of the webinar series was awarded the "Preis des Landes Berlin für
Alternativmethoden in Forschung und Lehre" in 20154. In 2018, the original concept was expanded to make the webinars continuously available. In agreement with the speakers, presentations were video-recorded and uploaded to the open access online schooling platform 3R-SMART ${ }^{5}$, which is integrated into the website of Laboratory Animal Science (LAS)-interactive ${ }^{6}$. The online offer will be expanded and updated constantly with further webinars.

To evaluate the impact of the webinars to teach participants 3R-relevant knowledge as well as to assess the acceptance of the webinar format, we asked all participants of the webinar carried out in 2018 to complete an online survey. In 2018, 45 people registered for on-site participation in the lecture hall (maximum capacity: 45), and 245 people registered for online participation. Additionally, 17 institutions or working groups registered and broadcast the webinar in seminar rooms or lecture halls for students, researchers and/or staff. Participants were from European countries (e.g., Austria, the Netherlands, Belgium, Luxembourg, France, Spain, England, Sweden, Denmark and Norway), the USA, Canada and China.

In 2018, speakers presented the following 3R topics:

1) Ethics and law (Justyna Chmielewska: Die rechtliche Einordnung von Tierversuchen [Legal aspects of animal experiments]; Prof. Dr Julia Dietrich: Ethische Abwägung von Tierversuchen [Ethical weighing of animal experiments])

2) Databases on animal testing and alternatives to animal testing (Dr Barbara Grune: Literature searches for alternatives to an-

\footnotetext{
1 https://ec.europa.eu/environment/chemicals/lab_animals/pdf/Endorsed_E-T.pdf (accessed 20.01.2020)

2 www.bb3r.de (accessed on 28.02.2020)

3 www.bb3r.de/graduiertenkolleg/Kurse-und-Kursprogramme/index.html (accessed 20.01.2020)

4 https://www.bb3r.de/news/Urkunde.html (accessed on 28.02.2020)

5 https://www.3r-smart.de/index.php?id=6834 (accessed 28.02.2020).

6 https://www.las-interactive.de (accessed 28.02.2020)
}

Received February 9, 2020;

(c) The Authors, 2020.

ALTEX 37(2), 300-303. doi:10.14573/altex.2002091

Correspondence: Katharina Hohlbaum, PhD

Freie Universität Berlin, Department of Veterinary Medicine

Institute of Animal Welfare, Animal Behavior, and Laboratory Animal Science

Königsweg 67 (Haus 21)

14163 Berlin, Germany

(katharina.hohlbaum@fu-berlin.de)
This is an Open Access article distributed under the terms of the Creative Commons Attribution 4.0 International license (http://creativecommons.org/licenses/by/4.0/) which permits unrestricted use, distribution and reproduction in any medium, provided the original work is appropriately cited. 
A

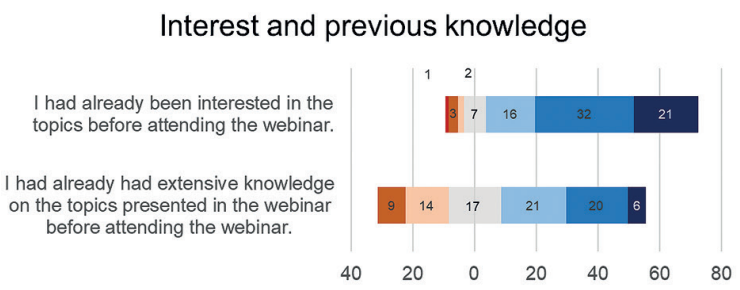

B

Application and relevance of webinar content

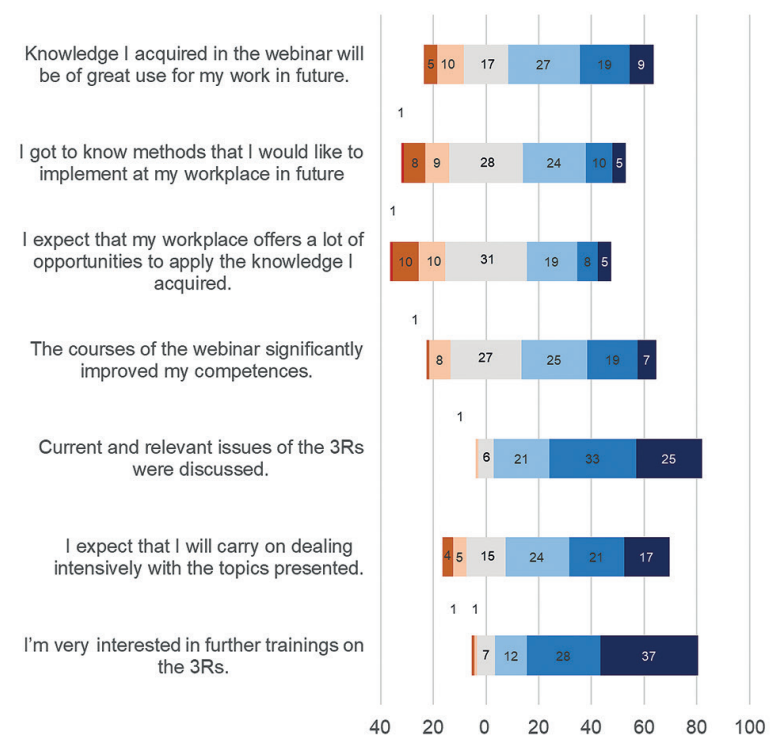

C

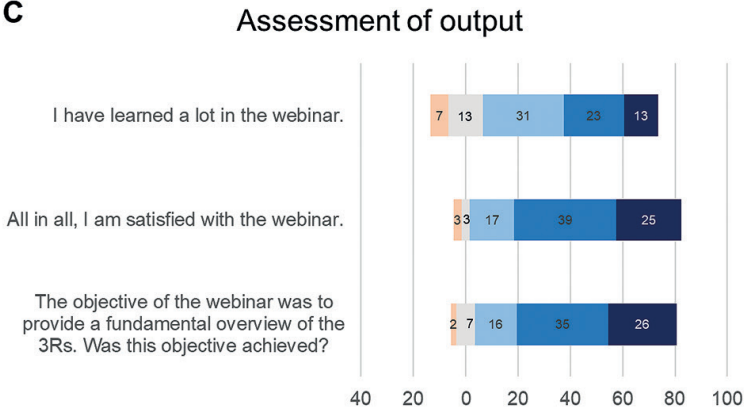

\section{Legend}

- strongly disagree

- disagree

- somewhat disaaree

neither agree nor disagree

nsomewhat agree

- agree

- strongly agree

Fig. 1: Evaluation of the webinar on 3R strategies in research and education in 2018

imal experiments; PD Dr Bettina Bert: Meta-analysis of nontechnical project summaries identifies research areas for 3R development)

3) Alternatives to animal use in education (Dr Mechthild Ladwig-Wiegard: Alternative methods as substitute and supplementary methods to animal experiments in education and training as applied 3R measures; PD Dr Michael Scheel: Can we apply 3R-principles to interventional radiology training and research)

4) Refinement strategies for laboratory rodents (Dr Charlotte Leidinger: Clicker training for laboratory mice; Dr Paulin Jirkof: Pain management in laboratory rodents)

5) Alternative methods for musculoskeletal disorders and alternative skin models (Moritz Pfeiffenberger: Modelling of musculoskeletal disorders in vitro - with complex processes to convincing systems; Dr Christian Zoschke: Organotypic skin models for improved preclinical drug development)

6) Human-on-chip and 3D bioprinting (Isabel Rütschle: Biology-inspired microphysiological systems (organs-on-a-chip) status quo and future perspectives; Prof. Dr Jens Kurreck: 3D bioprinting of organ models)
7) In vitro and in silico methods (Prof. Dr Bettina Seeger: Alternative methods for potency testing of botulinum neurotoxins; Dmitri Stepanov: Computer modelling of skin penetration)

8) Animal-based severity assessment (Dr Katharina Hohlbaum: Systematic assessment of well-being in mice for procedures using general anesthesia; Prof. Dr Lars Lewejohann: Behavioral phenotyping - refinement strategies)

The online survey was completed by 89 participants, including students, doctoral candidates, scientists from various fields, human physicians, veterinarians, animal welfare officers, directors of animal facilities, animal care takers, technical assistants, and a communications consultant for lab animal welfare. Most participants stated that they already had some previous knowledge $(66 \%)$ and also interest (84\%) in the topics presented in the webinar before attending (Fig. 1A). Participants were equally interested in all 3Rs (i.e., 58 people indicated interest in refinement, 53 in reduction, and 47 in replacement).

The majority of participants (approximately 90\%) found the extent of the content covered in the webinar courses and the level of difficulty as well as comprehensiveness exactly right. Almost everyone (92\%) agreed upon the actuality and relevance of 3R top- 
Tab. 1: Topics of webinars held in 2016, 2017 and 2018

\begin{tabular}{|c|c|c|}
\hline Replacement & Reduction & Refinement \\
\hline \multicolumn{3}{|c|}{ Ethics in animal experimentation } \\
\hline \multicolumn{3}{|c|}{ Animal welfare legislation } \\
\hline \multicolumn{3}{|c|}{ Responsibilities of the animal welfare officers } \\
\hline \multicolumn{3}{|c|}{ Databases on animal testing and alternatives to animal testing } \\
\hline $\begin{array}{l}\text { Current status and future prospects of } \\
\text { alternative methods }\end{array}$ & \multicolumn{2}{|l|}{ Imaging techniques } \\
\hline $\begin{array}{l}\text { Development process of alternative } \\
\text { methods }\end{array}$ & In-silico methods & Animal-based severity assessment \\
\hline $\begin{array}{l}\text { Alternative methods in veterinary, medical, } \\
\text { and biology education }\end{array}$ & CRISPR/Cas9 & Farm animals and fish in research \\
\hline \multirow{12}{*}{$\begin{array}{l}\text { Alternative methods in the following areas: } \\
\text { - Toxicity } \\
\text { - Genotoxicity } \\
\text { - Carcinogenicity } \\
\text { - Neurotoxicity } \\
\text { - Developmental toxicity } \\
\text { - Infectiology } \\
\text { - Eye irritation } \\
\text { - Skin irritation and absorption } \\
\text { - Skin disease models } \\
\text { - Musculoskeletal disorders models } \\
\text { - Lung models }\end{array}$} & Statistics & Animal training \\
\hline & & Pain management \\
\hline & & \\
\hline & & \\
\hline & & \\
\hline & & \\
\hline & & \\
\hline & & \\
\hline & & \\
\hline & & \\
\hline & & \\
\hline & & \\
\hline Human-on-chip & & \\
\hline 3D bioprinting & & \\
\hline Stem cells & & \\
\hline Alternative animal models, e.g., drosophila & & \\
\hline
\end{tabular}

ics that were presented. Application and relevance of the webinar content were rated very positively overall (Fig. 1B): Most of the participants agreed (strongly to somewhat) with the statement that the knowledge they acquired in the webinar would be of great use for their future work (63\%). Moreover, 46\% agreed (strongly to somewhat) that they would like to implement methods that were introduced. However, only $38 \%$ of participants expected (strong to somewhat agreement) that they would have the opportunity to apply the 3R knowledge at their workplace. More than half of the participants had the impression that the webinar significantly improved their competences $(59 \%)$ and expected that they would deal with the webinar topics further $(72 \%)$. The assessment of output revealed that the webinar gave participants an overview of the 3 Rs $(90 \%)$ (Fig. 1C). Overall, the participants stated that they learned a lot and were satisfied with the webinar (93\%).

The high number of participants $(89 \%)$ interested in further training underlines the high demand for education and training on 3R relevant knowledge in form of online educational services. Non-German speaking participants would like to attend a lecture on ethics held in English. A broad range of topics was suggested for future webinars (Tab. 2). Especially further refinement topics were highly demanded. We aim to cover these suggested topics in future webinars.

The webinar on 3R strategies in research and education offered as a free open educational resource was well received overall. Our survey pointed out that there is a high demand for education and training on 3R relevant knowledge, especially on refinement approaches, which may be due to the legal requirements under EU legislation (EU, 2010). The webinar on 3R strategies in research and education can significantly contribute to spreading a wide diversity of 3R knowledge and, thereby, foster the implementation of new $3 \mathrm{R}$ approaches. It is expected that the webinar participants will multiply the information by snowball effect. Since sharing and disseminating 3R knowl- 
Tab. 2: Topics for future webinars suggested by the participants

\begin{tabular}{|c|c|c|}
\hline Replacement & Reduction & Refinement \\
\hline \multicolumn{3}{|c|}{ Overview of applied 3R strategies } \\
\hline \multicolumn{3}{|c|}{ Toxicology studies } \\
\hline \multicolumn{3}{|c|}{ Regulatory studies (e.g., pharmaceutical safety assessment) } \\
\hline $\begin{array}{l}\text { Translation of findings in cell culture } \\
\text { models to the entire organism }\end{array}$ & Imaging techniques & Training of rodents \\
\hline Organoids & Reduction of variability in animal experiments & Animal handling techniques \\
\hline Microbiological standardization & & Animal welfare issues in breeding \\
\hline \multirow[t]{10}{*}{$\begin{array}{l}\text { Replacement in neuroscience studies and } \\
\text { other specific experiments }\end{array}$} & & $\begin{array}{l}\text { (overproduction, more efficlent breedıng, } \\
\text { severity assessment, e.g., systemic } \\
\text { lupus erythematosus, infectious diseases, } \\
\text { or other animal models) }\end{array}$ \\
\hline & & $\begin{array}{l}\text { New approaches on analgesia and } \\
\text { anesthesia in rats and mice }\end{array}$ \\
\hline & & Euthanasia \\
\hline & & Experimental design \\
\hline & & Animal testing approval \\
\hline & & $\begin{array}{l}\text { Refinement in animal husbandry and } \\
\text { housing }\end{array}$ \\
\hline & & $\begin{array}{l}\text { Refinement strategies for zebrafish } \\
\text { (e.g., husbandry and housing, enrichment, } \\
\text { analgesia, anesthesia, euthanasia) }\end{array}$ \\
\hline & & Refinement strategies for farm animals \\
\hline & & Rehoming \\
\hline & & $\begin{array}{l}\text { Refinement in neuroscience studies and } \\
\text { other specific experiments }\end{array}$ \\
\hline
\end{tabular}

edge is crucial to implementing the $3 \mathrm{Rs}$ in science, we hope that other academic and research institutions will be infected by our enthusiasm and also consider offering courses on the $3 \mathrm{Rs}$ as webinars. It may also be considered to broadcast selected talks held at $3 \mathrm{R}$ conferences like the EUSAAT Congress or the World Congress on Alternatives and Animal Use in the Life Sciences for those who cannot participate. Readers wishing to contribute as speakers to upcoming webinars are encouraged to contact the authors of this letter.

We are continuing the webinar introduced here in 2020 due to the high level of acceptance and great demand in the scope of the initiative Berlin 3R, even after the end of the funding period by the German Federal Ministry of Education and Research. Information on future webinars will be made available on the websites of BB3R ${ }^{2}$ and 3R-SMART ${ }^{5}$.

\section{References}

EU (2010). Directive 2010/63/EU of the European Parliament and of the council of 22 September 2010 on the protection of animals used for scientific purposes. Off J Eur Union L276, 33-79. http://data.europa.eu/eli/dir/2010/63/oj

Holley, T., Bowe, G., Campia, I. et al. (2016). JRC science for policy report. Accelerating progress in the Replacement, Reduction and Refinement of animal testing through better knowledge sharing. Luxembourg: Publications Office of the European Union. doi:10.2788/934083

Russel, W. and Burch, R. (1959). The Principles of Humane Experimental Technique. London, UK: Methuen.

\section{Funding}

The webinars held in 2016-2017 were initiated by the BerlinBrandenburg research platform BB3R (German Federal Ministry of Education and Research, grant number: 031A262A) and financed by prize money "Preis des Landes Berlin für Alternativmethoden in Forschung und Lehre" (prize to VK, MSK, CTR). In 2018, the webinar was funded by 3R-SMART (German Federal Ministry of Education and Research; grant number: 031L0113A). 